\title{
O MEIO AMBIENTE DO TRABALHO E OS PROCESSOS JUDICIAIS ELETRÔNICOS: 0 paradigma do mundo virtual e seus efeitos para os servidores forenses
}

\author{
Brenda Reis dos Anjos \\ Mestranda em Direito Ambiental pela Universidade Estadual do Amazonas (UEA), Graduada \\ em Direito pelo Centro Universitário de Ensino Superior do Amazonas (CIESA), sendo \\ também Graduanda finalista em Licenciatura em Letras Língua e Literatura Portuguesa pela \\ Universidade Federal do Amazonas (UFAM). Membro associado no Conselho Nacional \\ de Pesquisa e Pós-Graduação em Direito (CONPEDI). Pesquisadora atuante nos temas \\ relacionados ao Direito, Linguística, Literatura, Desenvolvimento, Meio Ambiente e Direitos \\ Socioambientais com ênfase em Direitos Indígenas. \\ End. eletrônico: brendadosanjos_m@hotmail.com
}

\section{RESUMO}

A informatização judicial é matéria de destaque na esfera jurídica contemporânea devido ao grande desafio de virtualização no meio ambiente de trabalho forense. A Lei de Informatização do Processo - LIP, n. 11.419/2006, trouxe novas ferramentas para o mundo das ciências jurídicas. Dada a complexidade do assunto, por este ser tema recente e de grande relevância, surge a necessidade de se esquadrinhar o assunto do Processo Eletrônico no Poder Judiciário do Brasil como instrumento de acesso à Justiça, de efetivação do Princípio Processual da Celeridade e suas respectivas implicações ao meio ambiente do trabalho. Os operadores do Direito enfrentam a imposição de acompanhar o constante processo de desenvolvimento tecnológico, estando expostos a riscos psicológicos e físicos advindos da imposição crescente de produtividade por consequência da informatização. Esse desafio torna necessária a análise do tema em paralelo à adoção de medidas preventivas, associadas à Ergonomia, para viabilizar um meio ambiente de trabalho sadio.

Palavras-chave: Meio ambiente do trabalho. Processo judicial eletrônico. Informatização judicial. Servidores forenses. Meio ambiente virtual. 
WORK ENVIRONMENT AND JUDICIAL CASES: The Paradigm Of The World And Their Effects Virtual For Forensic servers

\section{ABSTRACT}

Computerization judicial matter is prominent in contemporary legal sphere due to the challenge in virtualization environment in forensic work. Law Informatization Process - LIP, number 11.419/2006 brought new tools to the world of legal sciences. Given the complexity of the matter, to be recent topic of great importance, there is a need to scrutinize the issue Process Machine on judiciary in Brazil as a means of access to justice, the realization of the principle of procedural celerity and their implications to working environment. The operators of the right face the imposition of monitoring the constant technological development process being exposed to physical and psychological risks arising from the imposition of increased productivity as a result of computerization. This challenge makes it necessary to examine this matter in parallel with the adoption of preventive measures associated with Ergonomics for facilitating a healthy work environment.

Keywords: Environment Labour. Lawsuit Electronic. Judicial Informatization. Forensic Servers. Virtual Environment.

\section{INTRODUÇÃO}

O processo de informatização do Poder Judiciário afigura-se como tendência irreversível na busca da efetivação das metas processuais e da eliminação da morosidade processual no ordenamento jurídico brasileiro. Não obstante, sabe-se que as inovações tecnológicas no campo laboral trazem consigo um grande aparato de mudanças na vida dos profissionais que as utilizam e, por isso, não devem ser ignoradas visto que o meio ambiente do trabalho sadio é um direito fundamental consagrado na Carta Magna de 1988.

A maior parte das discussões que entornam a temática do processo judicial eletrônico debruçam-se basicamente no plano de efetividade da prestação jurisdicional e no respeito ao Princípio Processual da Celeridade, 
contudo a indiscutível relevância dessa abordagem não dá os contornos definitivos ao tema.

O presente ensaio tem por objetivo central suscitar a reflexão das implicações que o uso intenso de computadores, como instrumento de trabalho, pode ocasionar na vida do trabalhador caso não sejam tomadas as cautelas necessárias.

Atualmente, está mais claro entender que não é um único contexto isolado, por mais importante que este seja, que é capaz de orientar a formulação plena de uma política pública. Qualquer política instituída com o fim público, portanto, presumidamente, legítimo, deve levar em consideração um tratamento de forma ampla que não apenas aquela diretamente relacionada com o fim procurado, mas atenta às consequências que levam à consecução destes objetivos, pois esta, sim, é a verdadeira legitimidade. Não é diferente no processo eletrônico.

Sendo assim, o que muitas vezes não se percebe é que a Lei n. 11.419/2006 - que instituiu o processo eletrônico - possui como meta estatal, indiscutivelmente, a demanda por um serviço público célere e qualificado, porém a resposta a esses anseios não está necessariamente ligada ao cumprimento da lei pura e simplesmente, e sim ao padrão de comportamento que agora é exigido do servidor que opera nesses sistemas informatizados.

Ademais, a constante mudança no ambiente de trabalho gera automaticamente a necessidade de crescente atualização tecnológica por parte do profissional, podendo ocasionar problemas físicos e psicológicos advindos da insegurança desse trabalhador caso não cumpra o que lhe é esperado. Estresse, ansiedade, depressão, dentre outros problemas, estão cada vez mais sendo diagnosticados no mundo do "Sistema da Informação". O que se deve salientar é que de nada adiantam os meios eletrônicos se quem os manuseia (ser humano) tem sua saúde prejudicada, tornando seu trabalho insalubre. Além disso, é nítida e palpável a ligação entre um bom ambiente de trabalho e o rendimento do trabalhador.

Sabe-se que juntamente com métodos ágeis oferecidos aos profissionais está o pressuposto intrínseco de maior produção em curto espaço de tempo. Dessa maneira, o trabalhador se sente obrigado a cumprir os prazos processuais de forma célere sem que para isso disponha de uma estrutura adequada para seu conforto, disposição e bem-estar. O meio ambiente do trabalho é o local onde o profissional passa boa parte de seu dia, devendo este estar apto segundo os parâmetros ergonômicos e peculiares 
a cada ofício.

Tem-se assim, como objetivos específicos desta pesquisa, estudar as consequências trazidas pela era da informação, analisar os fatores positivos e negativos da implementação do processo judicial eletrônico no ordenamento jurídico pátrio, identificar os fatores positivos comprovados pela maior produção e celeridade processual, transparência e economia de recursos naturais, bem como fatores negativos perceptíveis através do diagnóstico de problemas oftalmológicos, dermatológicos, circulatórios, entre outros.

Longe de se esgotar o tema aqui proposto, nota-se que seu estudo minucioso possibilitará maior eficácia à Justiça, porquanto, estando inserido em um meio ambiente ecologicamente equilibrado - tal qual se é garantido constitucionalmente -, o servidor forense poderá cumprir seus objetivos processuais sem que para tanto agrida sua saúde e qualidade de vida, visto que não se deve proteger uma garantia em contramão de outra.

Com isso, o presente estudo elucidará, de forma clara, acerca do processo da Revolução do Conhecimento e seus aspectos reflexos para a sociedade contemporânea, apontando, ao final, contribuições para que o processo judicial eletrônico possa garantir maior desempenho na justiça brasileira sem atingir o meio ambiente de trabalho do servidor do Poder Judiciário.

\section{REVOLUÇÃO DO CONHECIMENTO E INFORMATIZAÇÃO JUDICIAL NO BRASIL}

Usa-se o termo Revolução do Conhecimento ou Revolução da Informação para fazer alusão ao período em que a sociedade inseriu-se em um novo estágio histórico de produção de riquezas e valores, no qual a informação e o conhecimento passaram a exercer o principal papel na atividade social, a partir do século $\mathrm{XX}^{1}$.

A composição, de contínuo crescimento, de redes mundiais de computadores agregou uma imensurável série de informações, tendo por consequência uma revolução econômica e tecnológica em todas as esferas do Estado contemporâneo.

O desenvolvimento tecnológico tem por primazia a facilidade de acesso à informação, bem como a facilidade de executar tarefas, auxilian-

${ }^{1}$ GUASQUE, 2013, p. 55-68. 
do assim nosso dia a dia. Desde a Antiguidade, o sistema da informatização transfigura a sociedade. Sob esse óbice, José Carlos de Araújo Almeida Filho $^{2}$ condensa o desenvolvimento histórico da informação:

Admitimos, porém, uma quebra de paradigma em pleno século XXI, apesar da ideia de uma sociedade de informação estar arraigada no homem desde a sua era primitiva, quando começam a se formar as sociedades e a necessidade de comunicação entre seus membros e de outros clãs e tribos. Com a invenção da prensa, por Gutemberg (século XV), temos uma maior propagação da informação e com a Revolução Francesa (século XVIII), desmoronam-se os tronos e a sociedade burguesa ascende ao poder, modificando as formas de pensar e agir. Prestigia-se a comunicação e a liberdade, com a promulgação da Declaração de Princípios da Revolução Francesa - inspiradora da Declaração Universal dos Direitos do Homem. [...] O grande paradigma que se enfrenta diante da ideia de uma nova sociedade e, consequentemente, reclamando do Direito novas concepções e métodos para a pacificação de seus conflitos, é a quebra de barreiras geográficas sem a necessidade da guerra.

A perspectiva de romper fronteiras geográficas alcançou amparo por meio do uso da internet de forma indispensável. Internet é a denominação utilizada para a rede de compartilhamento de informações, que, por volta da década de 1960, foi instituída nos Estados Unidos da América através do projeto militar ARPANET (Advanced Research Projects Agency), durante a época da "Guerra Fria". A respectiva rede foi criada objetivando a garantia da comunicação, da informação e do tráfego de dados em qualquer circunstância.

Nesse contexto torna-se essencial apontar a ótica de Castells ${ }^{3}$, da qual criou-se o conceito de Estado-Rede, que, por sua vez, advém da concepção de que é palpável a estruturação do não estruturável, ou seja, é possível manter a inovação e permitir saltos de desenvolvimento ainda que para isso sejam colocadas à tona as maneiras de manejo do mundo como outrora era disposto. O ideário do autor norteia a discussão sobre "um novo mundo" no qual a sociedade, a economia e a cultura passam a estar conectados através das tecnologias. Dessa maneira, acaba por surgir uma sociedade em rede, denominada de sociedade informacional. É essa sociedade, descrita pelo referido autor, a realidade atual na qual nos inseri-

\footnotetext{
${ }^{2}$ ALMEIDA FILHO, 2011, p. 51.

${ }^{3}$ CASTELLS, 2007, p. 30-35.
} 
mos - inclusive no Poder Judiciário.

Ademais, no dia 31 de maio de 1995, o Ministério das Comunicações do Brasil editou a Portaria n. 148/1995, a qual caracterizou "internet" como:

Nome genérico que designa o conjunto de redes, os meios de transmissão e comutação, roteadores, equipamentos e protocolos necessários à comunicação entre computadores, bem como os softwares e os dados contidos nesses computadores ${ }^{4}$.

A internet passou a ser intensamente utilizada pelos usuários, na década de 90, em todas as vias do conhecimento e da vida humana, associando-se ao cotidiano das pessoas em todos os seus aspectos: profissionais, pessoais, financeiros, entre outros.

O mundo atual, da "era on-line e instantânea", se define pelo ritmo acelerado, pela brevidade e pela urgência, no qual a sociedade é regida pelo fator tempo - este cada vez mais insuficiente em paralelo à propagação da informação - cada vez mais essencial.

Esse contexto gera dificuldades e conflitos que incumbem à ciência jurídica o dever de oferecer respostas para que esta siga a mutação constante da sociedade contemporânea. Há um paradoxo social, no qual de um lado tem-se uma sociedade dinâmica, e de outro uma justiça lenta. Nessa linha, por conta da morosidade do sistema processual judiciário, promulgou-se a Emenda Constitucional n. 45 no dia 08 de dezembro de 2004, também conhecida como "Reforma do Judiciário". Tal emenda estabeleceu, no rol de direitos e garantias fundamentais, o Princípio da Duração Razoável do Processo, no Artigo 5º LXXVIII da Constituição Federal de 1988, in verbis: "A todos, no âmbito judicial e administrativo, são assegurados a razoável duração do processo e os meios que garantam a celeridade de sua tramitação"s.

A vontade de solucionar problemas de gestão do Poder Judiciário por meio da implantação do processo judicial eletrônico no Brasil vem sendo esboçada há alguns anos. Originalmente, os profissionais do Direito faziam uso de computadores, eliminando por completo as máquinas de datilografar; em seguida, as secretárias judiciárias passam a fazer uso sistemas de gerenciamento da movimentação processual e, algum tempo de-

\footnotetext{
${ }^{4}$ BRASIL, 1995, s.p.

${ }^{5}$ BRASIL, 1988, s.p.
} 
pois, permitiram-se consultas externas sobre o andamento processual via internet $^{6}$.

A primeira lei a vislumbrar a origem do processo eletrônico no ordenamento jurídico brasileiro foi a Lei n. 9.800, de 26 de maio de 1999. Através dela, tornou-se possível a condução de dados para o exercício de atos processuais, sendo assim, as petições poderiam ser expostas por meio de máquinas que assim permitissem, como, por exemplo, o fac-símile ${ }^{7}$, todavia, posteriormente deveria ser juntado o original aos autos previamente transmitidos.

No tocante à implementação do processo judicial eletrônico, tem-se por precursor o Tribunal Regional Federal da $4^{\mathrm{a}}$ Região, visto que, ao editar o Provimento Normativo n. 01 de 10 de maio de 2004, instituiu normas para estabelecer os processos virtuais nos juizados especiais. Considera-se ser esse um plano piloto que possibilitou, posteriormente, a instauração do processo eletrônico em todos os âmbitos da Justiça Federal. Ademais, a Resolução n. 40, de 2007, tipificou a obrigatoriedade do trâmite eletrônico nos processos em tramitação no Tribunal supracitado, in verbis:

Art. $1^{\circ}$ - A tramitação dos processos de regulação, avaliação e supervisão de instituições e cursos superiores do sistema federal de educação superior será feita exclusivamente em meio eletrônico, no sistema e-MEC, e observará as disposições específicas desta Portaria e a legislação federal de processo administrativo, em especial os princípios da finalidade, motivação, razoabilidade, moralidade, interesse público, economia e celeridade processual e eficiência, aplicando-se, por analogia, as disposições pertinentes da Lei $n^{\circ} 11.419$, de 19 de dezembro de $2006^{8}$. (grifo nosso)

É necessário salientar que, somente com a Lei n. 11.419, de 19 de dezembro de 2006, o processo digital se impulsionou no Brasil, com o propósito principal de efetivar a celeridade processual, porém, deve-se sempre respeitar os princípios do ordenamento jurídico brasileiro além de velar pelo meio ambiente do trabalho sadio dos operadores do Direito, por conta das implicações que tais mudanças podem gerar.

$\overline{{ }^{6} \text { GUASQUE, 2013, p.55-68. }}$

${ }^{7}$ Fac-símile é toda cópia ou reprodução que apresenta uma grande semelhança com o original.

${ }^{8}$ BRASIL, 2007. 


\subsection{Processo Eletrônico}

O processo eletrônico está incluso no moderno campo das Ciências Jurídicas denominado de diversas formas como: Direito Eletrônico, Direito Digital, Direito Cibernético, ou ainda, Direito da Informática. Almeida Filho o conceitua:

\footnotetext{
É o conjunto de normas e conceitos doutrinários destinados ao estudo e normatização de toda e qualquer relação onde a informática seja o fator primário, gerando direitos e deveres secundários. É, ainda, o estudo abrangente com o auxílio de todas as normas codificadas de direito, a regular as relações dos mais diversos meios de comunicação, dentre eles os próprios da Informática? 9 .
}

Assim, a Lei n. 11.419/2006 trouxe inovações e desafios aos juristas devido ao modelo de tecnologia presente na Modernidade. Nesse contexto, tem-se a informatização e o uso intenso da internet em todas as áreas do contexto humano, inclusive nas ciências jurídicas, motivo que justifica o fato de o processo eletrônico significar um grande avanço tecnológico para o mundo jurídico, arraigado de perspectivas de "desafogar" a Justiça, desde que para isso não produza efeitos irreversíveis na saúde e qualidade do meio ambiente do trabalhador. Para tanto, é essencial o estudo minucioso e interdisciplinar do Direito, da Informática, da Segurança da Informação, de Ergonomia e do meio ambiente do trabalho, dado o caráter recente da justiça eletrônica no Brasil.

A aludida lei possui vinte e dois artigos e contém quatro aspectos primordiais, que são: a exposição de documentos eletrônicos, a comunicação dos atos processuais, o trâmite do processo de forma inteiramente digital e a certificação digital dos advogados.

Mesmo havendo a inserção de novos parâmetros e novas tecnologias, deve-se atentar também para o respeito aos direitos fundamentais, sob pena de nulidade do processo eletrônico. Entre o rol de garantias constitucionais, está a do meio ambiente ecologicamente equilibrado, estando intrínseco a essa definição o meio ambiente do trabalho - no qual a presente pesquisa visa repousar, além de outros, como o devido processo legal, da publicidade, da celeridade e do acesso à Justiça ${ }^{10}$.

\footnotetext{
${ }_{9}^{9}$ ALMEIDA FILHO, 2005, p. 85.

${ }^{10}$ CLEMENTINO 2007, p. 129.
} 
$\mathrm{O}$ ato de digitalizar documentos não equivale à ideia de processo eletrônico, visto que esse é muito mais amplo que aquele. $\mathrm{O}$ reflexo do processo eletrônico recai sobre um novo modo de conduta, ou seja, uma mudança no cotidiano do Judiciário brasileiro devido à imposição para com seus operadores objetivando que estes se adaptem de forma brusca e imediata a fim de acompanharem a contínua evolução dos meios eletrônicos.

Nessa esteira, o Supremo Tribunal Federal - STF - editou a Resolução 427, de 20 de abril de 2010, regulamentando o processo eletrônico em sua esfera. Ainda nessa linha, o STJ publicou a Resolução n. 14, de 28 de junho de 2013, enquanto a Justiça Trabalhista é responsável pelo ato conjunto CSJT/TST 120/2013, que altera a Resolução CSJT n. 94, de 2012, anteriormente vigente ${ }^{11}$. No âmbito da Justiça Estadual, pode-se citar como exemplo o Projudi, instalado no estado do Amazonas, no estado do Paraná e em outros. Atualmente, as referidas normas são as que se encontram em vigor, visto que a regulamentação do processo virtual sofre constantes, e necessárias, atualizações.

Sob essa perspectiva, Juliana Fioreze ${ }^{12}$ leciona que:

É certo que o Direito não pode permanecer estático frente ao desenvolvimento tecnológico, e sua modernização é imprescindível para que se alcance segurança jurídica nas relações mantidas na sociedade informatizada.

Ainda no que diz respeito ao inevitável uso dos atributos tecnológicos e da internet, salienta Gilberto Dupas acerca da ponderação e do bom-senso que tal ato exige de seus operadores:

Se não formos capazes de subordinar o desenfreado avanço tecnológico à moderação da moral e da razão - ou seja, ao bom uso da autodeterminação -, nossa espécie poderá estar pavimentando o caminho do poema de Robinson Jeffers: Um dia a Terra vai-se coçar, e sorrir, e sacudir para fora a humanidade ${ }^{13}$.

O Direito Processual tem como mister promover a pacificação dos conflitos presentes na sociedade, apontando métodos par solução desses. Ao analisar a relevância do processo, Mauro Cappelletti indica a fun-

\footnotetext{
${ }^{11}$ BRASIL, 2013, s.p.

${ }^{12}$ FIOREZE, 2009, p. 72.

${ }^{13}$ PAESANI, 2007, p. 77.
} 
ção social do processo como sendo instrumento de acesso à justiça. Ele dividiu sua abordagem em três facetas, sendo que a primeira refere-se à assistência judiciária para os desfavorecidos, a segunda à configuração dos interesses difusos e a terceira é uma espécie de construção intensificada do acesso à Justiça; em outras palavras, um novo paradigma, que abarca consigo o processo eletrônico e a informatização judicial ${ }^{14}$.

\section{O MEIO AMBIENTE DO TRABALHO E O PROCESSO JUDICIAL VIRTUAL}

Um dos princípios fundamentais da ordem constitucional brasileira democrática é a valorização do trabalho. A Constituição admite a importância da conduta laborativa como um dos meios essenciais de autoconfiança do ser humano, tanto no âmbito de sua peculiaridade quanto no âmbito de sua inserção social e familiar.

O quesito da valorização laboral está reiteradamente enfatizado pela Carta Magna de 1988. A partir de seu Preâmbulo, pode-se notar tal afirmação, prosseguindo nos fundamentos da República Federativa do Brasil (Art. $1^{\circ}$, III e IV) ao fixar, ao lado de outros, a dignidade da pessoa humana e os valores sociais do trabalho e da livre iniciativa:

Art. $1^{\circ}$ - A República Federativa do Brasil, formada pela união indissolúvel dos Estados e Municípios e do Distrito Federal, constitui-se em Estado Democrático de Direito e tem como fundamentos:

$[\ldots]$

III- a dignidade da pessoa humana;

IV - os valores sociais do trabalho e da livre iniciativa;

$[\ldots]^{15}$. (grifo nosso)

Continua-se, didaticamente, a trilhar tal vertente nos Princípios Fundamentais, bem como nos artigos $6^{\circ}$ e $7^{\circ}$, ao versar sobre a temática dos “direitos sociais", in verbis:

Art. $6^{\circ}$ - São direitos sociais a educação, a saúde, a alimentação, o trabalho, a moradia, o lazer, a segurança, a previdência social, a proteção à maternidade e à infância,

\footnotetext{
${ }^{14}$ CAPPELLETTI, 2002, p. 81.

${ }^{15}$ BRASIL, 1988.
} 
a assistência aos desamparados, na forma da Constituição.

$[\ldots]$

Art. $7^{\circ}$ - São direitos dos trabalhadores urbanos e rurais, além de outros que visem à melhoria de sua condição social:

$[\ldots]$

IV - salário mínimo, fixado em lei, nacionalmente unificado, capaz de atender a suas necessidades vitais básicas e às de sua família com moradia, alimentação, educação, saúde, lazer, vestuário, higiene, transporte e previdência social, com reajustes periódicos que lhe preservem o poder aquisitivo, sendo vedada sua vinculação para qualquer fim;

V - piso salarial proporcional à extensão e à complexidade do trabalho;

$[\ldots]$

$\mathrm{XV}$ - repouso semanal remunerado, preferencialmente aos domingos;

$[\ldots]^{16}$. (grifo nosso)

Além do plano da economia e da sociedade ao reger "Ordem Econômica e Financeira" com seus princípios gerais da atividade econômica (Art. 170) e, por fim, da Ordem Social e sua disposição geral (Art. 193), in verbis:

Art. 170 - A ordem econômica, fundada na valorização do trabalho humano e na livre iniciativa, tem por fim assegurar a todos existência digna, conforme os ditames da justiça social, observados os seguintes princípios [...]

$[\ldots]$

Art. 193 - A ordem social tem como base o primado do trabalho, e como objetivo o bem-estar e a justiça sociais ${ }^{17}$. (grifo nosso)

Acerca do meio ambiente do trabalho, tem-se que é "caracterizado pelo local onde o trabalhador desenvolve sua atividade profissional"18, englobando-se a zona judiciária onde os servidores forenses exercem seus ofícios, sendo um dos diversos gêneros que o conceito de meio ambiente tutela $^{19}$, sob amparo constitucional nos artigos 23, inciso VII, 170, inciso VI, 200, inciso VIII, e 225, caput e incisos da Constituição de $1988^{20}$,

\footnotetext{
${ }^{16}$ BRASIL, 1988.

${ }^{17}$ BRASIL, 1988.

${ }^{18}$ SIMON, 2013, s.p.

${ }^{19}$ SILVA, 2010, p.20.

${ }^{20}$ Art. 23, CF/88: "É competência comum da União, dos Estados, do Distrito Federal e dos Municí-
} 
inclusive para resguardar as condições de saúde do indivíduo - foco da pesquisa aqui alçada.

Na tipificação do direito fundamental ao meio ambiente ecologicamente equilibrado, estão inseridos seus múltiplos alcances: ecológico, urbano, cultural, imaterial e do trabalho, objeto deste estudo. Não se deve confundir, porém, meio ambiente do trabalho com a proteção do direito do trabalho, visto que este versa apenas no tocante às relações empregatícias com vínculo de subordinação, enquanto aquele tem por objeto jurídico a saúde e a segurança do trabalhador a fim de que este desfrute de qualidade de vida. Sob este contexto, José Afonso da Silva corrobora:

\begin{abstract}
Merece referência em separado o meio ambiente do trabalho como o local em que se desenrola boa parte da vida do trabalhador, cuja qualidade de vida está, por isso, em íntima dependência da qualidade daquele ambiente. É um meio ambiente que se insere no artificial, mas digno de tratamento especial, tanto que a Constituição o menciona explicitamente no art. 200, VIII, ao estabelecer que uma das atribuições do Sistema Único de Saúde consiste em elaborar a proteção do ambiente, nele compreendido o do trabalho. $\mathrm{O}$ ambiente do trabalho é protegido por uma série de normas constitucionais e legais destinadas a garantir-lhe condições de salubridade e segurança ${ }^{21}$.
\end{abstract}

Assim, nota-se que por meio de normas relativas à qualidade de higiene, de saúde e de segurança, a Carta Magna visa mitigar os riscos aos quais os trabalhadores estão expostos. Diversas convenções internacionais tutelam tal abordagem, sendo de merecido destaque a de n. 155, de 1981, que versa sobre o desenvolvimento de uma Política Nacional de Saúde, Segurança e Meio Ambiente do Trabalho por parte dos países, incluído nesta o local de trabalho, bem como os aparatos necessários para o desempenhar de suas tarefas. Através desse sistema, buscam-se determinar os riscos existentes nas atividades exercidas, além de promover a fiscalização e a realização de pesquisas de acidentes de trabalho em prol da efetivação

pios:

$[\ldots]$

VIII- proteger o meio ambiente e combater a poluição em qualquer de suas formas".

Art. 170, VI, CF/88: "[...] defesa do meio ambiente, inclusive mediante tratamento diferenciado conforme o impacto ambiental dos produtos e serviços e de seus processos de elaboração e prestação".

Art. 225, caput, $\mathrm{CF} / 88$ : "Todos têm direito ao meio ambiente ecologicamente equilibrado, bem de uso comum do povo e essencial à sadia qualidade de vida, impondo-se ao Poder Público e à coletividade o dever de defendê-lo e preservá-lo para as presentes e futuras gerações. [...]"

${ }^{21}$ SILVA, 2010, p. 21. 
da segurança nos locais de ofício.

Harvey S. Perloff ${ }^{22}$ assevera que:

\begin{abstract}
A qualidade do meio ambiente em que a gente vive, trabalha e se diverte influi consideravelmente na própria qualidade de vida. $\mathrm{O}$ meio ambiente pode ser satisfatório e atrativo, e permitir o desenvolvimento individual, ou pode ser nocivo, irritante e atrofiante.
\end{abstract}

Desse modo, conforme até aqui abordado, abstrai-se que o processo judicial eletrônico transportou a tecnologia rumo ao Direito Processual, por meio da reedição de atos processuais, permitindo assim que as partes e o juiz possam interagir com o processo. Pouco a pouco o processo físico vem sendo substituído pelo ambiente digital, contendo consigo os malefícios e benfeitorias gerados pela inovação virtual.

Perante o contexto da informatização judicial, advogados, magistrados, analistas judiciários e qualquer outro tipo de servidores forenses se veem diante de uma nova estrutura em seu ambiente de trabalho, centralizado no uso do computador, em monitores e redes de emissão de dados. Diante desse novo ambiente de trabalho, ao qual se impõe uma adaptação imediata por parte dos trabalhadores, depara-se com fatores de perigo à saúde dos mesmos, motivo esse que justifica a essencialidade da pesquisa proposta.

Adverte-se para o fato de que as normas de cunho ambiental, relacionadas ao meio ambiente de trabalho dos juristas - em que pese à adesão do processo eletrônico, lamentavelmente não foram antecedidas de um respectivo estudo de impacto ambiental e de um possível inventário ergonômico para preservação da saúde dos juízes e dos servidores. Não se atentou, ainda, para a implementação de ações que suprimam ou mitiguem os maiores riscos à saúde, advindos da inovação tecnológica no meio ambiente de trabalho.

É de competência da União, nos termos do Art. $37, \S 6^{0},{ }^{23}$ da Constituição Federal, a responsabilidade por danos ocasionados pelos seus agentes em face de terceiros. Com mais propriedade, a União se incumbirá pelos danos que atinjam seus agentes como consequência do uso inadequa-

\footnotetext{
22 PERLOFF, citado por SILVA, 2010, p. 22.

${ }^{23}$ Art. 37, $\S 6^{\circ}, \mathrm{CF} / 88$ : "As pessoas jurídicas de direito público e as de direito privado prestadoras de serviços públicos responderão pelos danos que seus agentes, nessa qualidade, causarem a terceiros, assegurado o direito de regresso contra o responsável nos casos de dolo ou culpa".
} 
do de novos meios eletrônicos no meio ambiente de trabalho das unidades judiciárias ${ }^{24}$.

O Tribunal Regional do Trabalho (TRT), por sua vez, responde pela adoção de programas voltados para a higiene e a segurança da atividade laboral, visando ao aperfeiçoamento do novo meio ambiente de trabalho por intermédio da subtração ou atenuação dos riscos à saúde física e mental de seus funcionários, sob pena de agir com culpa in vigilando ${ }^{25}$.

Faz-se necessário atentar que não se deve preterir a garantia fundamental ao meio ambiente de trabalho sadio, bem como a preservação da saúde dos agentes e servidores públicos do Poder Judiciário, por conta da inserção e manutenção do processo judicial eletrônico.

\subsection{Benefícios da virtualização do processo: celeridade e economia de custos e materiais ambientais}

Muitos são os desafios a serem enfrentados pela Justiça brasileira diante dos novos paradigmas de gestão e métodos de trabalho. Conforme visto no presente trabalho, a complexidade da utilização dos processos virtuais pelos órgãos judiciários não se abstém a eliminar a morosidade processual, visto que se deve garantir um meio ambiente de trabalho equilibrado a fim de que se opere o Direito com eficiência por parte dos servidores.

É essencial a análise cautelosa dos benefícios e, posteriormente, dos malefícios para que se observem os contrapesos da questão em foco, a partir de seus prós e contras, a fim de harmonizar o meio ambiente do Judiciário brasileiro.

\subsubsection{Celeridade processual}

Sem dúvidas, dentre os diversos fatores que justificam o empenho do processo judicial eletrônico em nosso ordenamento jurídico merece destaque a busca pela efetivação da celeridade processual. É de mútuo consenso que os órgãos judiciais brasileiros lutam diariamente contra os prazos processuais, porém a morosidade, na maioria das vezes, deixa a sociedade sem esperança de pleitear seus direitos frente ao Estado.

\footnotetext{
${ }^{24}$ BRASIL, 1988, s.p.

${ }^{25}$ A culpa in vigilando é aquela que decorre da falta de atenção com o procedimento de outrem, cujo ato ilícito o responsável deve pagar.
} 
O Princípio da Celeridade Processual zela amenizar a vagarosidade do trâmite processual brasileiro, garantia que se acredita tornar possível através da utilização do processo eletrônico. Nessa perspectiva, se espera que sejam reprimidos prejuízos de âmbito material e psicológico às partes que entram com litígios judiciais, decorrentes da longa tramitação processual, realidade vivenciada no Judiciário brasileiro, pública e notória em nossa sociedade.

Os doutrinadores que defendem o processo digital na esfera jurídica corroboram que ele permitirá o exercício da jurisdição além de uma ampla simplificação no tocante à comunicação dos atos processuais e a transmissão de peças processuais, dispensando o uso exacerbado de papel hoje necessário, o que implicaria em diminuição no tempo despendido com a comunicação desses atos processuais. A esse respeito, a legislação abarca diversas alterações procedimentais, criando um novo modo de execução, transmissão e armazenamento dos atos processuais, com o objetivo maior de estar "à disposição do sistema judiciário, provocando um desafogo, diante da possibilidade de maior agilidade na comunicação dos atos processuais e de todo o procedimento" 26 .

Por intermédio do uso processual em sua modalidade eletrônica, se erradicará o método de juntadas demasiadamente lento, bem como a realização de "carga" dos autos e juntada física de documentos, fazendo com que o processo se direcione de modo mais ágil à fase de julgamento.

Paralelamente, poder-se-ia esquivar dos extensos períodos em que o processo continua em secretarias do juízo à espera da juntada de documentos, autuação, certificações, entre outros exemplos, à medida que os serventuários, geralmente em quantidade escassa em comparação ao volume de processos que diariamente dão entrada no Judiciário, perduram absortos em diferentes ofícios, também inerentes ao exercício da jurisdição.

Nessa via, se concretiza a imposição constitucional da razoável duração do processo, melhorando intensamente a prestação jurisdicional, além de fornecer uma resposta mais adequada às demandas sociais.

Em fevereiro de 2010, realizou-se pesquisa de opinião com 300 pessoas que se encontravam nos bairros Boa Esperança, em Seropédica; Flamengo; Centro da Cidade do Rio de Janeiro; Barra da Tijuca; e Alcântara, em São Gonçalo, no Estado do Rio de Janeiro. Nessa ocasião, foram

${ }^{26}$ ALMEIDA FILHO, 2010, passim. 
entrevistadas 50 pessoas em cada bairro acima citado. Quando questionadas se acreditavam que a utilização do processo digital diminuiria o tempo de duração do processo na Justiça, 52\% dos interrogados responderam afirmativamente, enquanto $48 \%$ responderam de forma negativa ${ }^{27}$. As pessoas entrevistadas aparentavam crer que a virtualização processual é nova forma de vislumbre processual, que simplificaria a consulta, todavia, na visão do jurisdicionado, não modificaria de maneira significativa a agilidade da prestação jurisdicional.

Os resultados demonstram a percepção dos indivíduos questionados quanto ao tema, obviamente, já fadigados diante da falta de agilidade do Judiciário como prestador de serviço público.

\subsubsection{Economia de custos e materiais ambientais}

Outro fator de extrema relevância é a possibilidade de redução dos custos. Tal avanço é almejado por meio da implantação do processo sem autos de papel. Tal vantagem permitirá tornar o processo menos oneroso aos cofres estatais, aos litigantes e, especialmente, aos recursos naturais.

Será viável a economia de tempo e custos com transporte e armazenamento porquanto não se precisarão deslocar fisicamente os processos. Ademais, se diminuirá o valor de operacionalização e gestão das atividades dos serventuários da Justiça no exercício de suas funções, que poderão operar em mais de um processo ao mesmo tempo.

Edilberto Clementino (2009, p. 168) disserta que uma das principais vantagens do processo virtual é que a "distância entre a residência do titular do direito ofendido e o escritório do causídico, e o réu, e o fórum, e o tribunal e os tribunais superiores é a mesma: um clique do mouse". Tal aspecto procedimental também contribui de forma profícua para a redução das despesas com processo físico.

O processo eletrônico também propicia a redução da necessidade de grandes espaços físicos nos cartórios e escritórios que serviam para comportar os processos em papéis, isso também se traduz em uma economia e otimização de espaço.

Outro ponto a ser observado é a economia de cartuchos de impressão, que serão muito menos utilizados, ainda, aqueles que forem real-

${ }^{27}$ POPULAÇÃO..., 2010, s.p. 
mente necessários podem ser reciclados como, por exemplo, o Tribunal de Justiça do Rio de Janeiro vem praticando. Nesse sentido, afirma o Tribunal que:

[a] reciclagem de cartuchos, além de ser ecologicamente correta, pode ser classificada como economicamente viável já que para produzir cada cartucho são utilizados, em média, dois a cinco litros de petróleo e utiliza material plástico, que leva séculos para se decompor ${ }^{28}$.

Conclui-se que, com a digitalização dos processos e a sua tramitação totalmente digital, não se precisaria da formação física dos autos do processo com a utilização em grande escala de papel, posto que todos os procedimentos, certidões e quaisquer outros atos processuais seriam realizados de maneira eletrônica, por meio da rede de computadores, economizando papel, tempo de servidores e, por consequência, gastos.

\subsection{Segurança e Medicina do Trabalho: o fator da saúde física e men- tal no meio ambiente do trabalho do Poder Judiciário}

A segurança do trabalho é uma seara multidisciplinar que objetiva prevenir os riscos oriundos do trabalho. O relacionamento entre o homem e as máquinas já gerou diversas benfeitorias para a humanidade, todavia, trouxe em paralelo um enorme número de vítimas portadoras de doenças incapacitantes ou cuja plenitude física e psíquica foram abaladas.

Entre a variedade de máquinas a que temos acesso na "era da informatização", os computadores possuem característica ímpar, visto que nunca a sociedade desfrutou de um único meio eletrônico que estivesse presente na vida laboral da maioria dos trabalhadores, independentemente de seu campo profissional. Assim, vários questionamentos têm sido feitos no tocante aos perigos advindos do uso de computadores, em especial, aos riscos denominados ergonômicos ${ }^{29}$.

A Ergonomia é um ramo autônomo que se debruça sobre o estudo e a adequação do meio ambiente de trabalho às peculiaridades psicofisiológicas dos trabalhadores a fim de proporcionar conforto, ambiente saudável, boa qualidade de vida (visto que boa parte do nosso dia se dá no local onde

\footnotetext{
${ }^{28}$ MASSUDA, 2013, s.p.

${ }^{29}$ PINTO FILHO, 2008, p. 21.
} 
desempenhamos nosso ofício) e desempenho eficiente.

O ordenamento trabalhista do Brasil considera a essencialidade dessa ciência e, devido a isso, editou uma norma regulamentadora relativa ao tema (Norma Regulamentadora n. 17) ${ }^{30}$. Os riscos intrínsecos ao uso de computadores, entre os demais riscos ergonômicos, são a exigência de postura inadequada, o uso de mobília imprópria, a repetitividade de ações mecânicas, a exposição durante longas jornadas de trabalho, entre outros.

É oportuno mencionar que a Carta Mãe, nos termos do Artigo $7^{\circ}$, caput e incisos, versa sobre a proteção, saúde e segurança dos trabalhadores, in verbis:

Art. $7^{\circ}$ - São direitos dos trabalhadores urbanos e rurais, além de outros que visem à melhoria de sua condição social:

$[\ldots]$

XXII - redução dos riscos inerentes ao trabalho, por meio de normas de saúde, higiene e segurança;

XXIII - adicional de remuneração para as atividades penosas, insalubres ou perigosas, na forma da lei;

$[\ldots]$

XXVII - proteção em face da automação, na forma da lei;

XXVIII - seguro contra acidentes de trabalho, a cargo do empregador, sem excluir a indenização a que este está obrigado, quando incorrer em dolo ou culpa;

[...]. (grifo nosso)

Então, para que se impeça que a saúde e qualidade do meio ambiente dos servidores forenses, expostos à tecnologia, sejam afetadas, é preciso controlar e avaliar periodicamente os riscos, a partir de programas que visem garantir a segurança e a saúde por meio da ação de profissionais especializados. Atenta-se para o fato de que no dia a dia pouco se notam os pequenos danos, passando às vezes de forma imperceptível, porém a ação acumulativa pode gerar resultados catastróficos e por vezes irreversíveis.

No tocante específico dos profissionais do Poder Judiciário brasileiro, sabe-se que a partir da virtualização dos processos a prevenção dos perigos de natureza ergonômica deve ser redobrada, por conta do uso contínuo e diário do computador. Essa preocupação traz benefícios não só aos funcionários forenses como a toda sociedade que depende da tramitação

${ }^{30}$ Norma publicada pela Portaria GM n. 3.214, de 08 de junho de 1978. Última atualização feita através da Portaria SIT n. 13, de 21 de junho de 2007. 
processual, pois o bem-estar físico e psicológico do trabalhador implica diretamente no seu desempenho profissional.

Salienta-se que atrelada à ideia de informatização está a de produtividade e desempenho. Sobre esse ponto, nota-se um paradoxo: se o objetivo central da implantação dos processos digitais no Judiciário se dá por conta da busca da celeridade, bastaria ter máquinas aptas para tanto? Os responsáveis pelo manuseio, se não gozarem de boa saúde, poderão dar o respectivo andamento por meio do uso eletrônico?

A pressão enfrentada pelos servidores em vista da frequente exigência de adaptação imediata a novos meios de tecnologia, inseridos frequentemente no ambiente de trabalho, pode ocasionar depressão, estresse, insônia, entre outros fatores que abalam diretamente a saúde e o desempenho do mesmo.

Uma das patologias profissionais mais costumeiras ao uso de computadores é a chamada L.E.R. - Lesão por Esforços Repetitivos -, isso porque ela está associada a toda e qualquer atividade que exija o uso forçado e contínuo de grupos musculares somado a posturas erradas e não, exclusivamente, ao uso do computador em si. É fato que, com o uso do processo eletrônico, os serviços se tornam mais mecanizados, aumentando assim as chances de aquisição da supracitada L.E.R., bem como das denominadas D.O.R.T. - Doenças Osteomusculares Relacionadas ao Trabalho ${ }^{31}$.

Ademais, a centralização de funções em uma mesa de trabalho em frente a monitores (um destinado aos autos e outro para a estruturação dos atos processuais) por longos períodos implica outros fatores também ligados à ergonomia, como por exemplo: problemas de coluna, de postura; de dores de cabeça; de circulação sanguínea nos membros inferiores (como trombose e varizes); de visão e lubrificação dos olhos; de distúrbios no sono; distúrbios de comportamento; entre outros males.

A intensa exposição ao computador faz com que, de forma inevitável, o usuário pisque menos do que o habitual. Geralmente, o ambiente do computador é climatizado, fato que contribui para retirada da umidade do ar tornando-o mais seco, isso favorece a desidratação da córnea, gerando a Síndrome da Disfunção Lacrimal - Síndrome do "Olho Seco" e fortes dores na cabeça. A referida síndrome apresenta diversos graus a depender da intensidade de exposição aos monitores, porém, ainda que de "grau

${ }^{31}$ D.O.R.T.: são doenças caracterizadas pelo desgaste de estruturas do sistema músculo esquelético que atingem várias categorias profissionais. 
leve", acaba por alterar o cotidiano e bem-estar de quem a possui. Além disso, existem outros problemas oftalmológicos de dada origem, a título de exemplo: coceira, queimação, irritação, olhos avermelhados, visão distorcida e desconforto visual após o uso da máquina.

Acerca das corriqueiras dores de cabeça e dos problemas oftalmológicos já citados, há um procedimento simples e fundamental para minimizar tais sintomas: a iluminação adequada do ambiente de trabalho. Atitudes como organizar o posicionamento das mesas, tendo por base o local das janelas, a fim de evitar reflexos na tela do monitor e pausas regulares para descanso dos olhos pode gerar a facilidade visual do conteúdo ali aberto e a melhoria do conforto oftalmológico. Somado a isso, devemse cumprir as exigências de exames médicos anuais, inclusos os exames oftalmológicos.

Outro fator a ser pensado é o mobiliário apropriado para desempenho dos ofícios. Entre outros itens, as escrivaninhas, as mesas, as cadeiras, os encostos para os pés e os teclados da espécie ergonômica são caracterizados por sua flexibilidade e ajuste às peculiaridades de cada usuário de acordo com os quesitos: peso, altura, idade etc. A falta da devida cautela sobre esses fatores ocasiona tormentosos problemas além dos já aqui apontados. A permanência do funcionário na mesma posição durante muito tempo, acrescida da má postura, provoca tensões nas articulações, ligamentos e músculos além de problemas na coluna vertebral. As maiores consequências na área vertebral são artroses, lordoses, cifoses ou escolioses, bem como surgimento de lombalgia (fortíssimas dores na coluna), hérnias de disco (saliência do disco) e, até mesmo, problemas estéticos, como seios caídos e região abdominal proeminente.

Nessa seara, existem técnicas primordiais com a finalidade de prevenir doenças laborais pelo uso do computador, ainda que tal atividade homem-máquina desenvolvida em escritórios, órgãos públicos ou até mesmo em residências seja aparentemente segura.

Como se é possível notar, a posição do monitor deve estar com sua parte superior no nível dos olhos; a distância entre o monitor e o usuário deve equivaler à extensão do braço; o monitor deve ser ajustado a fim de evitar reflexos da iluminação na tela; os pés devem estar apoiados no chão ou em um suporte; os pulsos devem estar relaxados, porém não flexionados; se houver entrada de dados, deve ser usado um suporte para documentos, para evitar os movimentos repetidos do pescoço; o usuário deve fazer pausas regulares para descanso, levantar, caminhar, exercitar 
os pulsos e pescoço com movimentos de flexão e extensão, além de evitar atender telefonemas enquanto digita para não atrofiar o pescoço devido à inclinação.

Dentro de todo computador há um componente que emite luz, podendo esta gerar manchas na pele e alterações no hormônio da melatonina. Conhecida por luz visível, esse tipo de radiação, que também é emitida pelo sol, causa mudanças no DNA da epiderme, assim como os raios ultravioletas (UVA e UVB). Cabe dizer que a luz visível de ambientes fechados, apesar de menos prejudicial do que se exposição à luz solar, precisa ser aqui referida. Isso porque, de acordo com o FDA (Food and Drug Administration) - órgão americano que fiscaliza medicamentos e alimentos - oito horas de luz artificial equivalem a um minuto e vinte segundos de exposição solar, considerando um dia claro de verão.

Como já se viu, a concretização da informatização dos processos judiciais não passou por um prévio estudo de impacto ambiental, bem como por exames preventivos acerca da saúde e pelo respectivo inventário ergonômico do local de trabalho. O uso do computador, nos mais variados órgãos do Poder Judiciário, afigura-se como tendência irreversível, sobretudo ao vislumbrar as mais novas metas traçadas para o Judiciário por consequência dos processos virtuais.

Comprovando tal afirmativa está o causídico constatado no Rio Grande do Sul, especificamente no Tribunal Regional Federal (TRF) da $4^{\mathrm{a}}$ Região. Segundo pesquisa feita durante os meses de maio e junho de 2011, coordenada pelo Juiz Federal Cândido Alfredo Silva Leal Júnior, entre noventa e dois magistrados federais do referido estado, posteriormente à implantação do processo eletrônico em zonas judiciárias do TRF da $4^{\text {a }}$ Região, evento que se deu no início de 2010. Dos juízes interrogados, $78,89 \%$ constataram piora em sua saúde e seu bem-estar laboral com o processo sem autos de papel; $86,81 \%$ sentiram dificuldades oftalmológicas com o processo virtual; somente $19,10 \%$ não notaram dores físicas desde que iniciaram o uso do processo eletrônico; $95,56 \%$ acreditam que o processo eletrônico pode agravar sua saúde no futuro, $82,02 \%$ estão insatisfeitos com suas condições de trabalho em relação ao processo eletrônico e, um dos mais alarmantes dados colhidos: nenhum associado se sente adequadamente orientado para prevenir riscos de saúde advindos do processo eletrônico ${ }^{32}$.

${ }^{32}$ LEAL JÚNIOR, 2011, s.p. 
Trata-se, antes de tudo, do desafio, que se põe ao Judiciário, de desenvolver servidores e magistrados, elevando a potencialidade destes, porém evitando o surgimento e a disseminação dos sintomas molestos normalmente correlacionados com a má utilização de computadores. Decerto, a meta maior é priorizar a saúde, concretizando a defesa da vida e se empenhando para a efetividade do Primado da Dignidade da Pessoa Humana.

\section{A ESSENCIALIDADE DE EXAMES PERIÓDICOS PARA PRE- VENÇÃO DE DOENÇAS DECORRENTES DO USO EXCESSIVO DO COMPUTADOR E ASPECTOS ERGONÔMICOS}

Tendo em vista, portanto, a necessidade de combater os efeitos nocivos do uso contínuo de computadores pelos servidores do Poder Judiciário, é que se deve proceder a uma análise multidisciplinar do problema apresentado. É necessário verificar como a medicina do trabalho e as normas de segurança para o trabalhador têm contribuído para a correção desses efeitos negativos na saúde do trabalhador que utiliza os procedimentos eletrônicos durante o labor judicial. Não obstante o fato de que a virtualização do Poder Judiciário possa trazer benefícios como maior celeridade dos atos processuais, não se mostra o melhor caminho ignorar os efeitos negativos que essa mudança pode acarretar à saúde dos trabalhadores.

Deve-se salientar, ainda, que os danos ocasionados não se limitam somente ao âmbito físico. Além dos problemas ergonômicos, também é afetada a estrutura do trabalho do ser humano, uma vez que a automação passa a ser um objetivo a ser atingido e não um meio através do qual suas atividades criativas deveriam ser desenvolvidas de forma diferenciada. Esta crítica aponta para o perigo de que as novas tecnologias afetem as atividades cognitivas dos servidores e os reduzam a meros alimentadores do sistema informático, além da diminuição do contato entre as pessoas, servidores e advogados, por exemplo ${ }^{33}$, comprometendo-se a humanidade e a relação entre as pessoas no ambiente forense.

Partindo dessa premissa, no sentido de desenvolver uma análise crítica a respeito das possibilidades do fenômeno em estudo, serão desenvolvidos essencialmente dois tópicos que se mostram relevantes para esta mudança de postura no desenvolvimento de atividades que utilizem os processos judiciais eletrônicos. O primeiro refere-se à necessidade de realiza-

${ }^{33}$ MORESCO e SCHURHAUS, 2012, p. 58, 59. 
ção de um levantamento periódico da situação ergonômica dos servidores que lidam diretamente com o processo judicial virtual, a fim de que sejam conhecidos os principais efeitos negativos à saúde do trabalhador no que se refere à ergonomia. $\mathrm{O}$ segundo ponto a ser abordado, por sua vez, referese à demonstração da essencialidade de exames periódicos que atestem o status da saúde do trabalhador e que disponham de ferramentas que auxiliem na prevenção e mitigação desses danos. As duas medidas propostas, portanto, constituem-se da aplicação concreta do Princípio da Prevenção no meio ambiente do trabalho. O Princípio da Prevenção é amplamente adotado no que se refere à proteção do meio ambiente de modo geral.

Tendo em vista que, neste trabalho, adotamos a classificação de meio ambiente do trabalho como vertente do Direito Ambiental, infere-se que, necessariamente, está legitimada a aplicação do Princípio da Prevenção em sua consecução. Nesse sentido, o Princípio da Prevenção aponta para a necessidade de evitar danos advindos de situações que podem ser previstas e evitadas, dada a certeza científica possível de ser determinada. Enquanto o Princípio da Precaução atua na gestão de riscos "hipotéticos", o Princípio da Prevenção atua para evitar riscos "certos"34.

No presente caso, nota-se que há mecanismos dispostos pela medicina do trabalho e pelas normas trabalhistas aptos à verificação da situação e que podem oferecer certeza científica à análise e demonstrar os riscos concretos inerentes à atividade do servidor envolvendo processos judiciais eletrônicos. Dentre essas maneiras de averiguar a concretude dos danos, destacam-se duas possibilidades: a verificação periódica da ergonomia dos servidores e a realização de exames médicos periódicos para atestar os possíveis danos.

\subsection{Verificação periódica da ergonomia do servidor}

Primeiramente, a fim de demonstrar a importância do acompanhamento das condições ergonômicas dos servidores, é preciso conhecer o conceito de ergonomia. Segundo a Associação Brasileira de Ergonomia (ABERGO),

[Ergonomia é] uma disciplina científica relacionada ao entendimento das interações entre os seres humanos e outros elementos ou sistemas e à aplicação de teorias, prin-

${ }^{34}$ SILVA, 2004, p. 82. 
cípios, dados e métodos a projetos, a fim de otimizar o bem-estar humano e o desempenho global do sistema ${ }^{35}$.

Assim, a Ergonomia visa conceber ações e condições de trabalho que não alterem a saúde dos trabalhadores, além de também constituir um elemento fundamental para a manutenção da atividade econômica, melhorando a produtividade e reduzindo índices de retrabalho e absenteísmo ${ }^{36}$.

A ABERGO classifica, ainda, a Ergonomia em três tipos possíveis: a) a ergonomia física (relacionada às questões de anatomia humana, fisiologia e biomecânica); b) a ergonomia cognitiva (percepção, memória, raciocínio e etc.) e; c) ergonomia organizacional, que se refere à otimização dos sistemas sociotécnicos, das estruturas organizacionais, políticas e demais processos, também conhecida como macroergonomia ${ }^{37}$.

Apesar dessa classificação, Moresco e Schurhaus ${ }^{38}$ consideram $^{2}$ que, hodiernamente, o núcleo de preocupação da ergonomia, volta-se para os conjuntos constituídos pelos sistemas de produção automatizados e complexos informatizados na prestação dos serviços. É justamente ao que se refere a este núcleo que se voltou a discussão no presente texto. Foram justamente os desajustes neste âmbito que revelaram a necessidade de observância dos aspectos ergonômicos na atividade laboral dos servidores do Poder Judiciário, que envolva processos eletrônicos.

Conforme já observado e demonstrado, nas profissões de longa permanência diante do computador, é comum a apresentação de sintomas de degradação da saúde do trabalhador. No entanto, não é comum que se encontrem estudos aprofundados em relação a esses danos nos servidores que trabalhem com processos judiciais eletrônicos, até mesmo considerando-se a atualidade do tema. Não obstante, essa análise pode ser feita por meio da observância dos malefícios que essas condições de trabalho acarretam em atividades análogas, como por exemplo, os bancários, digitadores, operadores de telemarketing, entre outros.

No que se refere especificamente aos processos judiciais eletrônicos, há que se destacar como marco a criação do sistema SAJ (Sistema de Automação da Justiça), que modificou sobremaneira o Poder Judiciário

\footnotetext{
${ }^{35}$ ABERGO, 2012, p. 32.

${ }^{36}$ MORESCO e SCHURHAUS, 2012, p. 44.

${ }^{37}$ ABERGO, 2011, p. 71.

${ }^{38}$ MORESCO e SCHURHAUS, 2012, p. 45.
} 
brasileiro. Esse fato é corroborado por Moresco e Schurhaus ${ }^{39}$, que demonstram que atualmente o sistema é utilizado nos cartórios judiciais, gabinetes de magistrados e demais setores de fóruns e tribunais (em primeira e segunda instância), de modo que desde as etapas de cadastro e distribuição até o arquivamento do processo são controlados por esse software. Agregue-se a esse fato, a possibilidade de consulta integral dos autos pelo computador. Todas essas funcionalidades, por si só, já denotam o excessivo tempo de exposição ao computador que o servidor enfrentará, de modo que se torna necessária a verificação dos aspectos ergonômicos envolvidos, que podem comprometer a saúde do trabalhador e, por consequência, os resultados das atividades no âmbito do Judiciário.

Na Consolidação das Leis do Trabalho (Decreto-Lei n. 5.452 de 1943), em seu Capítulo V, a partir do Artigo 154, estão dispostas normas gerais sobre segurança e medicina do trabalho. Em matéria de ergonomia, no entanto, deve-se consultar a Norma Regulamentadora (NR) n. 17.

Segundo o Ministério do Trabalho, a NR foi elaborada inicialmente, visando à grande quantidade de casos de enfermidades entre trabalhadores que realizavam digitação e afins:

Em 1986, diante dos numerosos casos de tenossinovite ocupacional entre digitadores, os diretores da área de saúde do Sindicato dos Empregados em Empresa de Processamento de Dados no Estado de São Paulo - SINDPD/SP fizeram contato com a Delegacia Regional do Trabalho, em São Paulo - DRT/SP, buscando recursos para prevenir as referidas lesões.

Foi constituída uma equipe composta de médicos e engenheiros da DRT/SP e de representantes sindicais que, por meio de fiscalizações a várias empresas, verificou as condições de trabalho e as repercussões sobre a saúde desses trabalhadores, utilizando a análise ergonômica do trabalho. Em todas as avaliações, foi constatada a presença de fatores que sabidamente contribuíam para o aparecimento das Lesões por Esforço Repetitivo - LER: o pagamento de prêmios de produção, a ausência de pausas, a prática de horas-extras e a dupla jornada de trabalho, dentre outros.

Portanto, nota-se que a observação concreta de danos à saúde dos trabalhadores, especialmente em ambientes fechados que utilizam digitação, constituiu um dos principais fatores para o estabelecimento de normas

${ }^{39}$ MORESCO e SCHURHAUS, 2012, p. 53. 
de segurança que procurassem evitar tais danos.

No que se refere ao trabalho do serventuário da Justiça, que lida com processos eletrônicos, é possível aplicar a NR n. 17, primeiramente, no que se refere à adequação do mobiliário para a execução das tarefas:

\subsection{Mobiliário dos postos de trabalho.}

17.3.1. Sempre que o trabalho puder ser executado na posição sentada, o posto de trabalho deve ser planejado ou adaptado para esta posição.

17.3.2. Para trabalho manual sentado ou que tenha de ser feito em pé, as bancadas, mesas, escrivaninhas e os painéis devem proporcionar ao trabalhador condições de boa postura, visualização e operação e devem atender aos seguintes requisitos mínimos: a) ter altura e características da superfície de trabalho compatíveis com o tipo de atividade, com a distância requerida dos olhos ao campo de trabalho e com a altura do assento; b) ter área de trabalho de fácil alcance e visualização pelo trabalhador; c) ter características dimensionais que possibilitem posicionamento e movimentação adequados dos segmentos corporais. (grifo nosso)

No caso dos servidores em estudo, veja-se que esses executam suas tarefas sentados, de modo que, nessa situação, é atribuída a observância de tais normas, tanto por parte dos servidores como por parte dos empregadores, cabendo a estes prover os recursos necessários para que o mobiliário esteja adequado às necessidades dos funcionários.

Nos itens que seguem a NR, também é exigido que os assentos utilizados nos postos de trabalho atendam a requisitos mínimos de conforto, como altura ajustável à estatura do trabalhador e à natureza da função exercida; pouca ou nenhuma conformação na base do assento; borda frontal arredondada; encosto com forma levemente adaptada ao corpo para proteção da região lombar, além de apoio para os pés.

Especificamente no que se refere ao trabalho envolvendo digitação e leitura eletrônica, a NR n. 17, estabelece o seguinte:

17.4.2. Nas atividades que envolvam leitura de documentos para digitação, datilografia ou mecanografia deve:

a) ser fornecido suporte adequado para documentos que possa ser ajustado proporcionando boa postura, visualização e operação, evitando movimentação frequente do pescoço e fadiga visual;

b) ser utilizado documento de fácil legibilidade sempre que possível, sendo vedada a utilização do papel brilhante, ou de qualquer outro tipo que provoque ofuscamen- 
to.

17.4.3. Os equipamentos utilizados no processamento eletrônico de dados com terminais de vídeo devem observar o seguinte:

a) condições de mobilidade suficientes para permitir o ajuste da tela do equipamento à iluminação do ambiente, protegendo-a contra reflexos, e proporcionar corretos ângulos de visibilidade ao trabalhador;

b) o teclado deve ser independente e ter mobilidade, permitindo ao trabalhador ajustá-lo de acordo com as tarefas a serem executadas;

c) a tela, o teclado e o suporte para documentos devem ser colocados de maneira que as distâncias olho-tela, olho-teclado e olho-documento sejam aproximadamente iguais;

d) serem posicionados em superfícies de trabalho com altura ajustável.

(grifo nosso)

Portanto, para estar adequado às normas relativas ao trabalho exercido no manuseio de processos eletrônicos, o Poder Judiciário teria que prover todos esses recursos a seus servidores. Além disso, ainda há normas relativas aos tempos de pausa para quem trabalha com digitação que, segundo o item 17.6.4 da NR, é de, no mínimo, uma pausa de 10 minutos para cada 50 minutos trabalhados. Por esses motivos, caberia um levantamento em todos os âmbitos do Judiciário, a fim de verificar o exato cumprimento das normas de segurança e determinar os passos em direção à sua observância integral.

Assim, tendo em vista que o servidor ficará durante muito tempo à frente do computador, a norma estabelece que deverão ser providenciados equipamentos que permitam a correta postura e posicionamento de pescoço, mãos, braços, coluna e pernas do funcionário. Além do conforto corporal, também é necessário resguardar a visão do servidor, uma vez que terá que fazer exposição diária dos olhos à luz e aos reflexos da tela do computador.

\subsection{Exames periódicos anuais}

Para lograr o controle dos danos causados à saúde dos trabalhadores, a Consolidação das Leis do Trabalho, em seu Artigo 168, determina que é obrigatório o exame médico, às expensas do empregador tanto no caso de demissão (para verificar se a atividade exercida ocasionou danos à sua saúde), bem como os chamados exames complementares, dependen- 
do da situação. O Ministério do Trabalho determina, ainda, a realização e periodicidade de exames médicos de acordo com o risco da atividade e o tempo de exposição e etc. (Art. 168 , II, $\S 1^{\circ}, 2^{\circ}, 3^{\circ}, 4^{\circ}$ e $5^{\circ}$ da CLT).

A realização de exames periódicos anuais pode diagnosticar danos que venham sendo ocasionados, de modo que, por meio do diagnóstico, seja possível interromper o fator que esteja causando ou agravando a enfermidade no servidor. A aplicação desses exames periódicos corresponde à aplicação do Princípio da Prevenção no meio ambiente do trabalho, conforme já demonstrado anteriormente.

Atualmente, esta necessidade de prevenção de doenças ocupacionais é corroborada pela criação do Programa de Controle Médico de Saúde Ocupacional (PCMSO), que determina a necessidade do Exame Médico Periódico, conforme a NR n. 17:

7.4.3.2 no exame médico periódico, de acordo com os intervalos mínimos de tempo abaixo discriminados:

a) para trabalhadores expostos a riscos ou a situações de trabalho que impliquem o desencadeamento ou agravamento de doença ocupacional, ou, ainda, para aqueles que sejam portadores de doenças crônicas, os exames deverão ser repetidos:

a.1) a cada ano ou a intervalos menores, a critério do médico encarregado, ou se notificado pelo médico agente da inspeção do trabalho, ou, ainda, como resultado de negociação coletiva de trabalho;

[...]. (grifo nosso)

Assim, tendo em vista que a atividade dos servidores da Justiça que utilizam diariamente os processos judiciais eletrônicos é uma atividade potencialmente causadora de danos à saúde dos trabalhadores, mostra-se necessária a realização desses exames periódicos como medida preventiva.

\section{CONSIDERAÇÕES FINAIS}

A imposição de que o trabalhador esteja em constante adaptação e aumento de produtividade é consequência da "era da informatização". A meta de se findar com a morosidade processual costumeira no Brasil, apesar de ter grande relevância e ser fundada constitucionalmente, deve ser exercida com cautela.

O processo judicial eletrônico veio como "uma luz no fim do 
túnel" para a sociedade que tanto se sente distante do Poder Judiciário brasileiro. A simplificação do acesso à Justiça, a economia dos recursos naturais e a tramitação célere das atividades processuais possibilitadas através desse instrumento realmente merecem destaque. No entanto, não se deve olhar algo tão complexo apenas sob uma óptica, visto que o meio ambiente do trabalho garante ao profissional seu direito fundamental a um local laboral sadio e que não agrida sua saúde. Assim, o presente trabalho procurou apontar medidas que possam mitigar os danos advindos do uso constante dos meios eletrônicos na esfera forense.

Acredita-se que programas voltados à prevenção de doenças de cunho oftalmológico, circulatório, dermatológico, entre outras, ocasionadas pelo uso excessivo do computador, podem auxiliar no controle e prevenção através de exames periódicos e aplicabilidade de princípios ergonômicos. Ademais, a Medicina do Trabalho foi criteriosa ao explanar que atividades sujeitas ao extremo desgaste de atividades repetitivas como: os bancários, os jornalistas, os médicos, os telefonistas devem ter suas jornadas de trabalho diminuídas bem como devem ser respeitados os necessários intervalos. Analogicamente os servidores forenses podem ser inclusos nesse rol exemplificativo, visto que também dispõem de trabalho centralizado em uma única máquina que exige, portanto, a mesma postura e os mesmos movimentos durante todo o trabalho.

Conclui-se que atrelada à adoção e implantação dos processos judiciais eletrônicos no ordenamento jurídico brasileiro está a necessidade de criação, fiscalização e controle dos riscos oriundos do meio ambiente de trabalho dos juristas do Brasil. Desse modo, poder-se-ia analisar e acompanhar o curso de tal procedimento e suas respectivas consequências da virtualização processual sem que, para tanto, já se tenham danos em nível irreversível.

\section{REFERÊNCIAS}

ABERGO. O que é Ergonomia? Disponível em <http://www.abergo.org. br>. Acesso em: jan. 2012.

ALMEIDA FILHO, José Carlos de. Processo eletrônico e teoria geral do processo eletrônico: a informatização judicial no Brasil. 4. ed. Rio de Janeiro: Forense, 2011.

ALMEIDA FILHO, José Carlos de Araújo. Manual de informática e Di- 
reito de Informática. Rio de Janeiro: Forense, 2005.

BRASIL. Constituição da República Federativa. Congresso Nacional. Brasília, 1988. Disponível em: <http://www.planalto.gov.br/ccivil_03/ constituicao/constituicao.htm>. Acesso em: 01 ago. de 2013.

. Decreto-Lei N. 5.452, de $1^{0}$ de maio de 1943. Aprova a Consolidação das Leis do Trabalho. Brasília: Senado Federal, 1943.

. Lei N. 9.800, de 26 de maio de 1999. Permite às partes a utilização de sistema de transmissão de dados para a prática de atos processuais. Disponível em: <http://www.planalto.gov.br/ccivil_03/leis/L9800.htm>. Acesso em: 21 jul. de 2013.

. Lei N. 11.419, de 19 de dezembro de 2006. Dispõe sobre a informatização do processo judicial; altera a Lei n. 5.869, de 11 de janeiro de 1973 - Código de Processo Civil. Disponível em: <http://www.planalto. gov.br/ccivil_03/_ato2004-2006/2006/lei/111419.htm>. Acesso: 22 jul. de 2013.

. Manual de aplicação da Norma Regulamentadora n. 17. 2. ed. - Brasília: Ministério do Trabalho e Emprego/ SIT, 2002.

. Ministério da Educação - Portaria n. 40 de 12 de dezembro de 2007. Brasília, 2007. Disponível em: <http://meclegis.mec.gov.br/documento/view/id/17>. Acesso em: 20 jul. de 2013.

. Norma Regulamentadora n. 17 (NR 17). Disponível em: $<$ http:// portal.mte.gov.br/data/files/FF8080812BE914E6012BEFBAD7064803/ nr_17.pdf $>$ Acesso em: 23 ago. 2013.

. Portaria n. 148 de 31 de maio de 1995. Aprova a Norma $n$. 004/95 - Uso da Rede Pública de Telecomunicações para acesso à Internet. Disponível em: <http://legislacao.anatel.gov.br/normas-do-mc/78-portaria-148> . Acesso em: 20 ago. de 2013.

Provimento n. 01 de 10 de maio de 2004, do Tribunal Regional do Trabalho da 4 Região. Determina normas complementares para regulamentação do Sistema e-proc. Disponível em: $<$ http://www2.trf4.jus. $\mathrm{br} / \mathrm{trf4} /$ upload/arquivos/leg_normas_adm/provimento0104.pdf $>$. Acesso em: 13 ago. 2013. 
. Resolução STJ n. 14 de 28 junho de 2013. Regulamenta o processo judicial eletrônico no Superior Tribunal de Justiça. Disponível em: $<$ http://bdjur.stj.jus.br/xmlui/bitstream/handle/2011/61239/Res\%20_14_ 2013_PRE.pdf?sequence=4>. Acesso em: 20 ago. 2013.

CAPPELLETTI, Mauro; GARTH Bryan. Acesso à justiça. Tradução: Ellen Gracie Northfleet. Porto Alegre: Sergio Antonio Fabris, 2002.

CASTELLS, Manuel. A sociedade em rede - a era da informação: economia, sociedade e cultura, v. 1. Tradução: Roneide Venâncio Majer e Jussara Simões. São Paulo: Paz e Terra, 2007.

CLEMENTINO, Edilberto Barbosa. Processo judicial eletrônico - o uso eletrônico na comunicação de atos e tramitação de documentos processuais sob o enfoque histórico e principiológico, em conformidade com a Lei 11.419, de 19.12.2006. Curitiba: Juruá, 2007, p. 129.

FIOREZE, Juliana. Videoconferência no processo penal brasileiro - Interrogatório on-line. 2. ed. Curitiba: Juruá, 2009.

GUASQUE, Bárbara. Política Judiciária e o Processo Eletrônico: eficácia socioeconômica. Disponível em: $<\mathrm{http}$ ://revistaseletronicas.pucrs. br/ojs/index.php/fadir/article/viewFile/12139/9064>. Acesso em: 23 jul. 2013.

LEAL JÚNIOR, Cândido Alfredo Silva. Processo eletrônico e a saúde dos magistrados federais no Rio Grande do Sul. Disponível em: $<$ http:// www.ibrajus.org.br/revista/artigo.asp?idArtigo $=218>$. Acesso em: 23 jul. 2013.

MASSUDA, Vanessa. O sistema eletrônico judicial na ótica ambiental: problema ambiental, solução e impactos econômicos. Disponível em: $<\mathrm{http}$ //www.ibrajus.org.br/revista/artigo.asp?idArtigo=172>. Acesso em: 09 ago. de 2013.

MORESCO, Adriana Kátia e SCHURHAUS, Ari Dorvalino. Os reflexos da automação na organização do trabalho no judiciário catarinense. In: JACOBSEN, Alessandra de Linhares; OLÍVIO, Luis Carlos. Tópicos destacados na gestão do judiciário catarinense. v. 1. Florianópolis: Boiteux, 2012. 
PAESANI, Liliana Minardi. Direito e Internet: Liberdade de informação, privacidade e responsabilidade civil. 3. ed. São Paulo: Atlas S.A., 2007.

PINTO FILHO, João Carlos. Computadores provocam acidentes de trabalho? Disponível em: <http:/www.segurancanotrabalho.eng.br/artigos/ computadores.html>. Acesso em: 09 ago. 2013.POPULAÇÃO reclama da lentidão do judiciário, aponta pesquisa da FGV. O GLOBO - política, 04 fev. 2010. Disponível em: $<$ http://oglobo.globo.com/politica/populacao-reclama-da-lentidao-do-judiciario-aponta-pesquisa-da-fgv-3057428> Acesso em: 20 ago. 2013.

SILVA, José Afonso da. Direito Ambiental Constitucional. São Paulo: Malheiros, 2010.

SILVA, Solange Teles. Princípio da precaução: uma nova postura em face dos riscos e incertezas científicas. In: PLATIAU, Ana Flávia Barros; VARELLA, Marcelo Dias. Princípio da precaução. Belo Horizonte: Del Rey, 2004.

SIMÓN, Sandra Lia. A proteção constitucional do meio ambiente do trabalho. Disponível em: $<$ http://www.gentevidaeconsumo.org.br/prof_ convidados/sandra_lia/protecao_constitucional.htm>. Acesso em: 11 ago. 2013.

Recebido: $31 / 10 / 2013$

Aceito: $24 / 01 / 2014$ 